\title{
GLOSSY MUTANTS OF MAIZE
}

\section{CHEMISTRY OF GLOSSY 4, GLOSSY 8, GLOSSY 15 AND GLOSSY 18 SURFACE WAXES*}

\author{
G. BIANCHI, P. AVATO and F. SALAMINI \\ Istituto di Chimica organica, Viale Taramelli 10, 27100 Pavia, Italy and \\ Istituto sperimentale per la Cerealicoltura, Sezione di Bergamo, via Stezzano 24, \\ 24100 Bergamo, Italy
}

Received 8.i.79

\section{Summary}

Modifications of chemical composition of surface waxes are induced by the recessive alleles of the $g l-4, g l-8, g l-15$ and $g l-18$ loci. Mutant $g l-4$ blocks the elongation of long chain wax molecules at the $\mathrm{C}_{30}-\mathrm{C}_{32}$ step. $g l-8$ and $g l-18$ mimic the action of $g l-1$ and $g l-7$, and may affect a very early stage of the biosynthetic pathway leading to long chain compounds or, alternatively interfere with the supply of wax precursors. $g l-15$ shows both an unusual spectrum of n-alkanes, in that the percentage of even chain compounds is higher than normal, and an abnormal synthesis of esterified primary alcohols of $\mathrm{C}_{16}$ and $\mathrm{C}_{18}$ chain lengths.

\section{INTRODUGTION}

THE leaf surface of maize seedlings is covered by epicuticular waxes (Bianchi and Marchesi, 1960; Lorenzoni and Salamini, 1975). Coe and Neuffer (1977) list 13 independent genes interfering with wax synthesis and accumulation. The modifications of wax chemical composition induced by the recessive alleles at the $g l-1, g l-2, g l-3, g l-5$ and $g l-7$ loci have been described previously (Bianchi et al., 1975, 1977, 1978). In this paper the results of a study of the chemical composition of the waxes produced by seedlings homozygous for the mutant alleles $g l-4, g l-8, g l-15$ and $g l-18$ are reported.

\section{Materials AND Methods}

The four mutants were obtained from the Maize Genetics Cooperative, Urbana, Illinois and backcrossed four times to the inbred WF9. The latter was then considered the normal $G l$ type. Mutant and normal genotypes were grown in a greenhouse during May 1977. Plants were collected at the fourth-fifth leaf stage of growth. Waxes were extracted by dipping the seedlings in chloroform for 45-60 sec. and fractionated by column chromatography to give n-alkanes, aldehydes, alcohols and esters (Bianchi et al., 1975). The esters were converted to methyl esters and alcohols by refluxing with 10 per cent methanolic hydrogen chloride and benzene for 24 hours. Gas-liquid chromatography (GLC) analysis of the homologous terms within each class of compounds was carried out as described (Bianchi et al., 1977).

* This work was supported in part by CNR (Rome); Grant no. CT 77.00138.06. 
TABLE 1

Composition of waxes of normal $\mathrm{Gl}$, and mutant gl-4, gl-8, gl-15 and gl-18 seedlings

\begin{tabular}{|c|c|c|c|c|c|c|c|c|c|c|}
\hline \multirow[b]{2}{*}{ Components } & \multicolumn{5}{|c|}{ Percentage } & \multicolumn{5}{|c|}{$\mathrm{mg} / 1000 \mathrm{~g}$ fresh weight } \\
\hline & Gl & gl-4 & gl-8 & gl-15 & gl-18 & Gl & gl-4 & $\mathrm{gl}-8$ & gl-15 & gl-18 \\
\hline $\begin{array}{l}\text { Alkanes } \\
\text { Aldehydes }\end{array}$ & $\begin{array}{r}1.4 \\
20 \cdot 4\end{array}$ & $\begin{array}{r}0 \cdot 2 \\
15 \cdot 7\end{array}$ & $\begin{array}{r}1 \cdot 1 \\
11 \cdot 5\end{array}$ & $\begin{array}{r}4 \cdot 9 \\
19 \cdot 9\end{array}$ & $\begin{array}{l}2 \cdot 4 \\
4 \cdot 3\end{array}$ & $\begin{array}{r}8 \cdot 1 \\
118 \cdot 3\end{array}$ & $\begin{array}{r}0 \cdot 5 \\
40 \cdot 1\end{array}$ & $\begin{array}{r}2 \cdot 0 \\
20 \cdot 0\end{array}$ & $\begin{array}{l}21 \cdot 6 \\
88 \cdot 8\end{array}$ & $\begin{array}{r}8 \cdot 8 \\
16 \cdot 1\end{array}$ \\
\hline Alcohols & $62 \cdot 7$ & $41 \cdot 9$ & $49 \cdot 4$ & $55 \cdot 0$ & $56 \cdot 6$ & $363 \cdot 7$ & $107 \cdot 2$ & $86 \cdot 8$ & $242 \cdot 8$ & $209 \cdot 4$ \\
\hline Esters & $15 \cdot 5$ & $42 \cdot 2$ & $38 \cdot 0$ & $20 \cdot 2$ & $36 \cdot 7$ & $89 \cdot 9$ & $108 \cdot 1$ & $66 \cdot 7$ & $39 \cdot 3$ & $135 \cdot 6$ \\
\hline Total & - & - & - & - & - & $580 \cdot 0$ & $255 \cdot 9$ & $175 \cdot 5$ & $441 \cdot 7$ & $369 \cdot 9$ \\
\hline$\%$ of no & - & - & - & - & - & 100 & $44 \cdot 1$ & $30 \cdot 3$ & $76 \cdot 2$ & $63 \cdot 8$ \\
\hline
\end{tabular}

\section{Results}

The composition of normal and mutant waxes is reported in table 1 . The four mutants have higher percentages of esters than the normal genotype. However, if the results are expressed as $\mathrm{mg}$ of esters per $1000 \mathrm{~g}$ of fresh weight, their quantities appear similar to the normal, except for $g l-18$ which accumulates more esters than the others. The percentages of aldehydes and free alcohols are considerably reduced in $g l-4$ and $g l-18$. The same pattern is found also on a fresh weight basis for $g l-4, g l-8$ and $g l-18$. The alkane fraction of $g l-4$ is lower $(0.2$ per cent) while it is higher ( 4.9 per cent) in the case of $g l-15$.

The percent distribution of homologous chains of wax classes is shown in table 2. The dominant chain lengths of the n-alkanes, aldehydes and alcohols of mutant $g l-4$ are shorter by two carbon units compared with the same classes of compounds in the normal plant. In glu4, the $\mathrm{G}_{\mathbf{3 0}}$ chains $\left(\mathrm{C}_{29}\right.$ in the alkane fraction) prevail while the normal plant synthesises almost entirely the $\mathrm{C}_{32}$ homologues $\left(\mathrm{G}_{31}\right.$ for the alkanes).

Mutations $g l-8$ and $g l-18$ differ less from the normal genotype. The long molecules in the waxes extracted from these mutations are those found in normal wax. The two mutations, however, reduce drastically the overall amounts of all the compounds synthesised except esters (table 1). This result suggests that $g l-8$ and $g l-18$ both show an early partial block in the synthesis of long chain molecules; alternatively an abnormally low supply of precursors may cause the reduced rate of wax synthesis in these mutations. gl-15 shows minor although peculiar modifications in wax composition. As in the normal genotype the $\mathrm{C}_{32}$ chain constitutes 100 per cent of the aldehydes and free alcohols of this mutant. The spectrum of n-alkanes of $g l-15$ is unusual in two respects; firstly there is a considerable increase in short chain homologues, secondly the percentage of even chain components is exceptionally high $(21.7$ per cent). The esterified primary alcohols show an unusual composition (table 2) having more than 50 per cent cetyl $\left(\mathrm{C}_{16}\right)$ and stearyl $\left(\mathrm{C}_{18}\right)$ alcohols and 39 per cent of hentriacontanol, while the intermediate chains $\left(\mathrm{C}_{20}\right.$ to $\left.\mathrm{C}_{30}\right)$, which are the dominant constituents of the other three mutants, are present in small amounts.

\section{Discussion}

The four glossy mutants studied, clearly interfere with epicuticular wax synthesis. Mutant $g l-4$ blocks the elongation of long chain molecules at the 


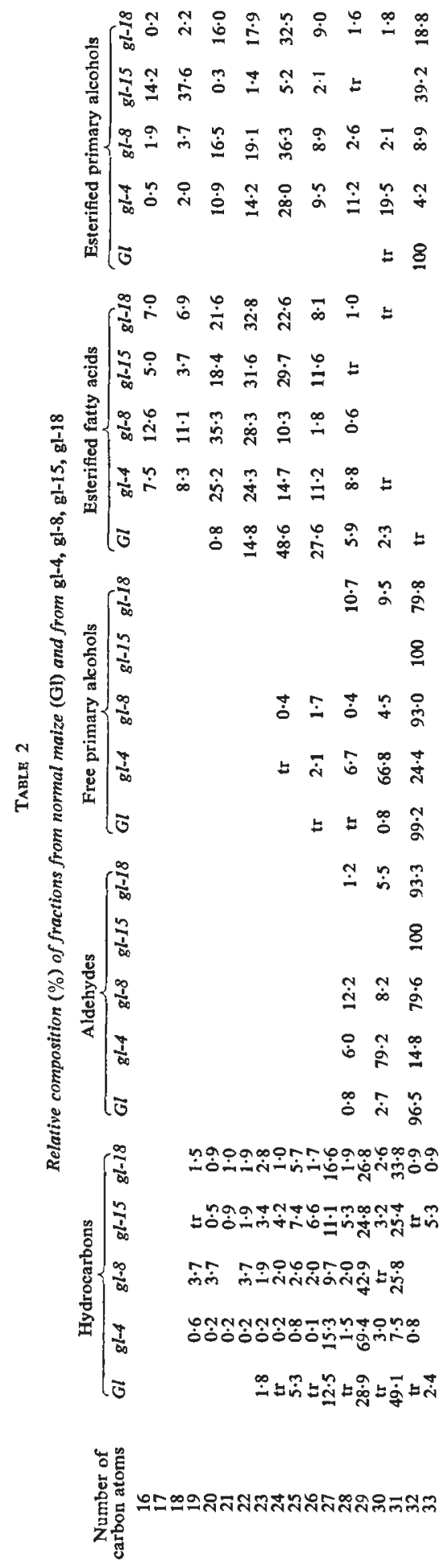




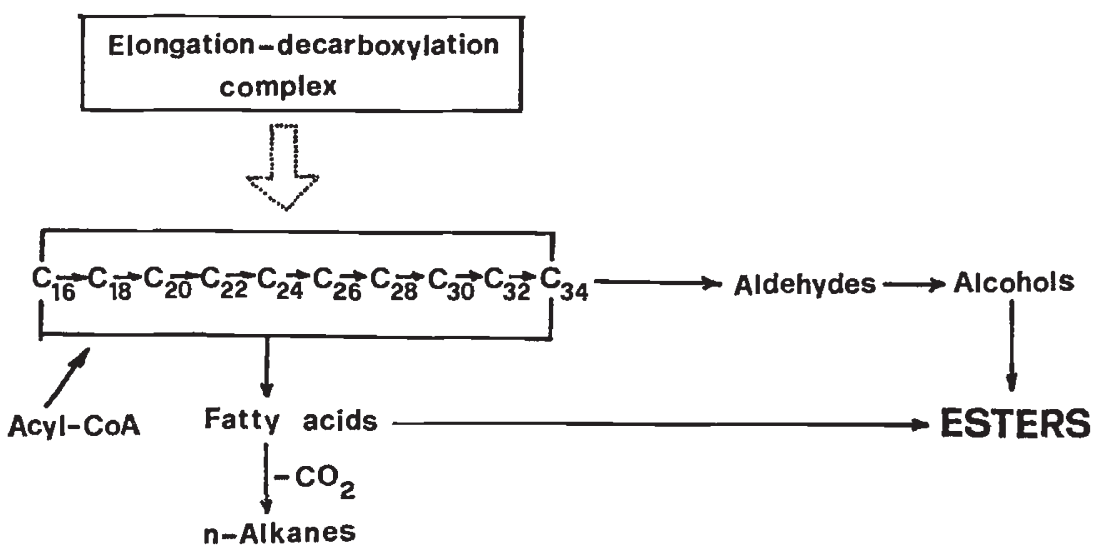

Fig. 1.-Wax biosynthesis of plant surface waxes (Kolattukudy, 1969, 1970).

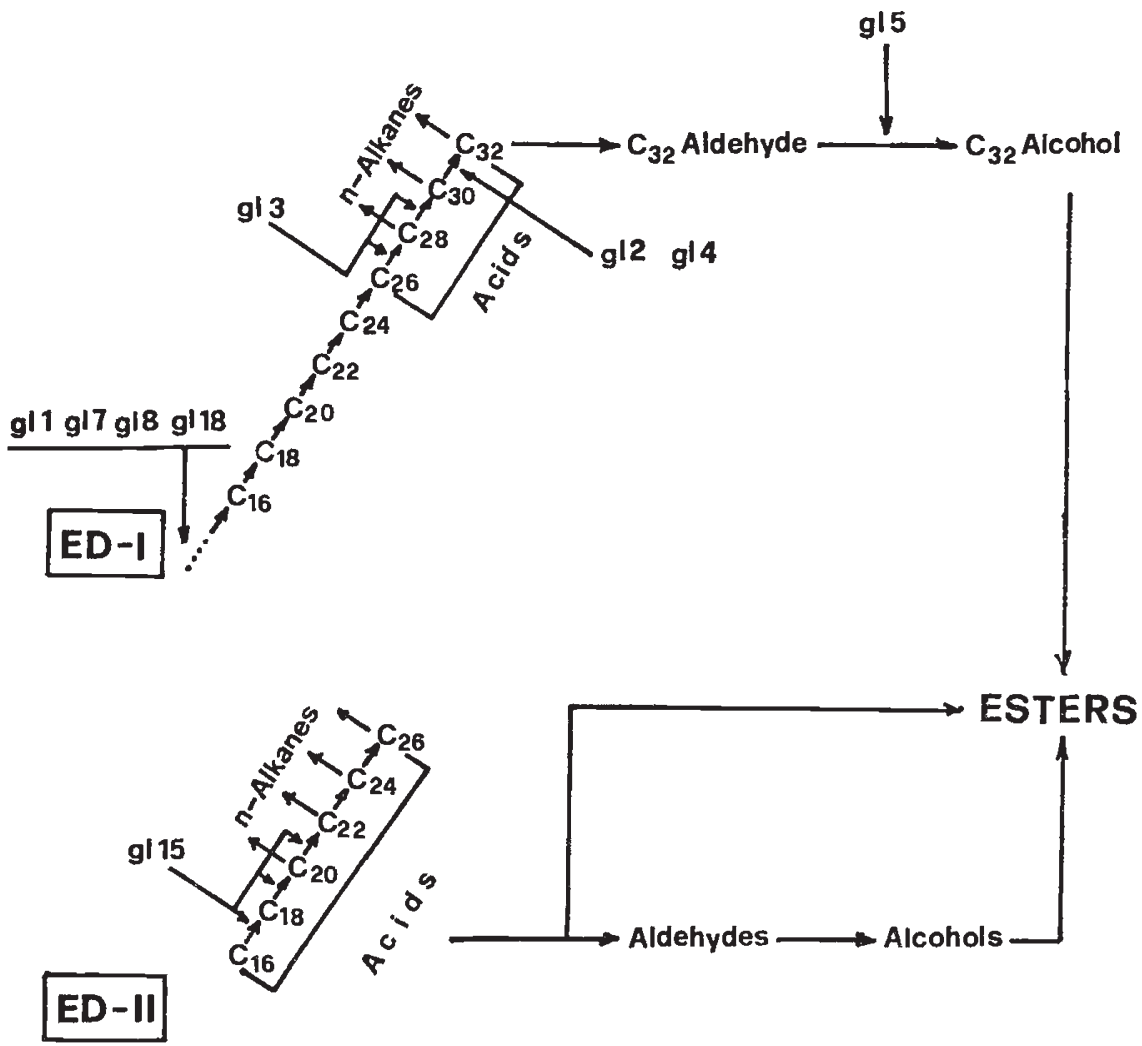

Fig. 2.-Wax biosynthesis of maize surface waxes. This pathway derives from that of fig. 1 together with the evidence provided by the mutation studies. In the scheme the major blocks induced by nine independent mutations are reported. 
$\mathrm{C}_{30} \rightarrow \mathrm{C}_{32}$ step, resembling the action of the recessive allele at the $g l-2$ locus (Bianchi et al., 1975). A mutation interfering with the last elongation step, as in $g l-2$ and $g l-4$ of maize, has also been described for Brassica oleracea (Macy and Barber, 1970; Macey, 1974). The kind of metabolic modification brought about by $g l-8$ and $g l-18$ is not as clearly definable, and resembles that of $g l-1$ and $g l-7$. The biosynthetic pathway leading to long chain compounds appears affected at a very early stage or, alternatively, the supply of precursors is abnormally low (Bianchi et al., 1977).

The most plausible biosynthetic pathway for wax synthesis is represented by the scheme of fig. 1, Kolattukudy $(1969 ; 1970)$ and verified for normal maize by Bianchi and Salamini (1975). Further work on wax synthesis in maize (Bianchi et al., 1975, 1977, 1978) indicates the existence of two elongation-decarboxylation complexes: ED-I, related to n-alkane, aldehyde and free alcohol synthesis, and ED-II responsible mainly for ester synthesis. The results discussed in this paper support the modified wax biosynthetic scheme shown in fig. 2. In the scheme are indicated the major effects of mutations, those described in this paper together with those found for the others previously studied. According to this $g l-15$ is effective somewhere between $\mathrm{C}_{18}$ and $\mathrm{C}_{22}$ of ED-II. As a result there is an accumulation of alcohols of 16 or 18 carbon atoms which are promptly incorporated into esters. Moreover, the ED-II complex releases, or does not accept many, short chain fatty acids, and these are therefore converted to n-alkanes by decarboxylation. In addition, ED-II of $g l-15$ appears to have lost its strict specificity towards the synthesis of odd numbered n-alkanes, and more even chain n-alkanes are produced according to well documented biochemical mechanisms (Kolattukudy, 1976).

\section{REFERENGES}

Bianchi, G., AVAto, P., AND salamini, F. 1975. Glossy mutants of maize. VI. Chemical constituents of glossy-2 epicuticular waxes. Maydica, 20, 165-173.

Bianchi, G., AVATO, P., AND SAlAmini, F. 1977. Glossy mutants of maize. VII. Chemistry of glossy-1, glossy-3 and glossy-7 epicuticular waxes. Maydica, 22, 9-17.

BIANCHI, G., AVATO, P., AND SALAMINI, F. 1978. Glossy mutants of maize. VIII. Accumulation of fatty aldehydes in surface waxes of $\mathrm{gl5}$ maize seedlings. Biochem. Gen. 16, 1015-1021.

BIANCHI, A., AND MARGHESI, G. 1960. The surface of the leaf in normal and glossy maize seedling. Z. Vererbungls., 91, 214-219.

BIANCHr, G., AND SAlamini, F. 1975. Glossy mutants of maize. IV. Chemical composition of normal epicuticular waxes. Maydica, 20, 1-3.

COE, E. H., AND NEUfFER, M. G. 1977. The genetics of corn. In Corn and Corn Improvement, ed. G. F. Sprague, pp. 111-223. Am. Soc. Agronomy, Madison, USA.

KolatTuKUDY, P. E. 1969. Biosynthesis of surface lipids. Science, 159, 498-505.

kolattuxudy, P. E. 1970. Biosynthesis of cuticular lipids. Ann. Rev. Plant Physiol., 21, 165-192.

KolAtTUKUDY, P. E. (Ed). 1976. Chemistry and biochemistry of natural waxes, p. 289. Elsevier, Amsterdam-Oxford-New York.

LoRENzoni, C., AND SALAmini, F. 1975. Glossy mutants of maize. V. Morphology of the epicuticular waxes. Maydica, 20, 5-19.

MACEY, M. J. X. 1974. Wax synthesis in Brassica oleracea as modified by trichloro acetic acid and glossy mutations. Phytochemistry, 13, 1353-1358.

MACEY, M. J. K., AND BARBER, H. N. 1970. Chemical genetics of wax formation on leaves of Brassica oleracea. Phytochemistry, 9, 13-23. 